\title{
Elevated temperature material properties of stainless steel alloys
}

\author{
L. Gardner ${ }^{1}$, A. Insausti ${ }^{2}$, K. T. Ng$^{3}$ and M. Ashraf ${ }^{4}$ \\ ${ }^{1}$ Senior Lecturer in Structural Engineering, Imperial College London, UK \\ ${ }^{2}$ Visiting academic, Imperial College London, UK \\ ${ }^{3}$ Project Coordinator, Shanghai Ji Xiang Properties Co., Ltd. \\ ${ }^{4}$ Lecturer in Structural Engineering, University of Queensland, Australia
}

\begin{abstract}
Appropriate assessment of the fire resistance of structures depends largely on the ability to accurately predict the material response at elevated temperature. The material characteristics of stainless steel differ from those of carbon steel due to the high alloy content. These differences have been explored in some detail at room temperature, whilst those at elevated temperatures have been less closely scrutinised. This paper presents an overview and reappraisal of previous pertinent research, together with an evaluation of existing elevated temperature stainless steel stress-strain test data and previously proposed material models. On the basis of examination of all available test data, much of which have been recently generated, revised strength and stiffness reduction factors at elevated temperatures for a range of grades of stainless steel have been proposed, including four grades not previously covered by existing structural fire design guidance. A total of eight sets of strength reduction factors are currently provided for different grades of stainless steel in EN 1993-1-2 and the Euro Inox/ SCI Design Manual for Structural Stainless Steel, compared to a single set for carbon steel. A number of sets of reduction factors is appropriate for stainless steel since the elevated temperature properties can vary markedly between different grades, but this has to be justified with sufficient test data and balanced against ease of design - it has been proposed herein that the eight sets of reduction factors be rationalised on the basis of
\end{abstract}


grouping grades that exhibit similar elevated temperature properties. In addition to more accurate prediction of discrete features of the elevated temperature material stress-strain response of stainless steel (i.e. strength and stiffness reduction factors), a material model for the continuous prediction of the stress-strain response by means of a modified compound Ramberg-Osgood formulation has also been proposed. The proposed model is less complex than the current provisions of EN 1993-1-2, more accurate when compared to test results, and the model parameters have a clear physical significance.

\section{Keywords}

Anisothermal, Elevated temperature, Fire design, Isothermal, Material modelling, RambergOsgood, Stainless steel, Stress-strain, Structures.

\section{Notation}

$$
\begin{aligned}
& \mathrm{k}_{0.2, \theta}=\sigma_{0.2, \theta} / \sigma_{0.2} \\
& \mathrm{k}_{2 \%, \theta}=\quad \text { Factor for determining } \sigma_{\mathrm{t} 2.0, \theta} \\
& \mathrm{k}_{\mathrm{E}, \theta}=\mathrm{E}_{\theta} / \mathrm{E} \\
& \mathrm{k}_{\mathrm{u}, \theta}=\sigma_{\mathrm{u}, \theta} / \sigma_{\mathrm{u}} \\
& \mathrm{k}_{\mathrm{y}, \theta}=\sigma_{\mathrm{t} 2.0, \theta} / \sigma_{0.2} \\
& \mathrm{E}=\text { Young's modulus at room temperature } \\
& \mathrm{E}_{0.2}=\text { Tangent modulus at the } 0.2 \% \text { proof stress at room temperature } \\
& \mathrm{E}_{0.2, \theta}=\text { Tangent modulus at the } 0.2 \% \text { proof stress at elevated temperature } \theta \\
& \mathrm{E}_{\theta}=\text { Young's modulus at elevated temperature } \theta \\
& \mathrm{n}=\text { Ramberg-Osgood }(\mathrm{R}-\mathrm{O}) \text { exponent at room temperature } \\
& \mathrm{n}_{0.2,1.0}=\text { Exponent stage } 2 \text { of compound R-O formulation at room temperature } \\
& \mathrm{n}_{\theta} \quad=\quad \text { Ramberg-Osgood exponent at elevated temperatures } \\
& \mathrm{n}_{\theta}^{\prime}=\text { Exponent stage } 2 \text { of compound R-O formulation at elevated temperatures } \\
& \theta=\text { Temperature } \\
& \varepsilon \quad=\quad \text { Strain }
\end{aligned}
$$


$\varepsilon_{t 0.2}=\quad$ Total strain corresponding to $\sigma_{0.2}$

$\varepsilon_{\mathrm{t} 1.0}=$ Total strain corresponding to $\sigma_{1.0}$

$\varepsilon_{\mathrm{u}, \theta}=$ Ultimate strain at elevated temperature $\theta$

$\sigma \quad=\quad$ Stress

$\sigma_{0.2}=0.2 \%$ proof strength at room temperature

$\sigma_{1.0}=1.0 \%$ proof strength at room temperature

$\sigma_{0.2, \theta}=0.2 \%$ proof strength at elevated temperature $\theta$

$\sigma_{\mathrm{t} 2.0, \theta}=$ Strength at $2 \%$ total strain at elevated temperature $\theta$

$\sigma_{\mathrm{u}}=$ Ultimate tensile strength at room temperature

$\sigma_{\mathrm{u}, \theta}=$ Ultimate tensile strength at elevated temperature $\theta$ 


\section{Introduction}

At both room temperature and elevated temperature, the material characteristics of stainless steel differ from those of carbon steel due to the high alloy content. At room temperature, stainless steel displays a more rounded stress-strain response than carbon steel and no sharply defined yield point, together with a higher ratio of ultimate-to-yield stress and greater ductility. At elevated temperatures stainless steel generally exhibits better retention of strength and stiffness in comparison to carbon steel. For a structure under fire conditions, these material properties are beneficial. Austenitic stainless steel, in particular, shows the best combination of strength, oxidation resistance and elevated temperature properties for long service, high temperature industrial applications and has been successfully employed for such purposes (with operating temperatures of around $550^{\circ} \mathrm{C}$ ) for many years [1,2]. Recent research [3-8] has examined the suitability of employing stainless steel for fire resistant structural applications, where the demands are very different from those in long service industrial applications. For instance, for structures in fire, the duration of exposure to high temperatures will be relatively short, while the temperatures reached may exceed $1000^{\circ} \mathrm{C}$. Additionally, owing to the low probability of occurrence of fire, large plastic deformations are tolerable in the structural members, provided overall structural collapse can be avoided. General background information related to the behaviour of steel structures at elevated temperatures and guidance on design for fire safety may be found in [9] and [10].

Appropriate assessment of the fire resistance of stainless steel structures depends largely on the ability to accurately predict the material response at elevated temperature. This paper presents an overview and reappraisal of existing pertinent research, proposes strength and stiffness reduction factors at elevated temperatures for a range of grades of stainless steel, some of which are not covered in existing design guidance, and describes a modified compound Ramberg-Osgood material model suitable for elevated temperatures. Use of the compound Ramberg-Osgood material model is now commonplace for modelling the nonlinear response of stainless steel at room temperature. At elevated temperatures, although the degree of nonlinearity changes, the basic rounded form of the stress-strain curve remains the same. The proposed modified material model utilises the material strength parameters currently employed for fire design in Eurocode 3, namely the elevated temperature $0.2 \%$ proof strength $\sigma_{0.2, \theta}$ and the strength at $2 \%$ total strain $\sigma_{\mathrm{t} 2.0, \theta}$. 


\section{Literature review}

General reviews of the structural use and design of stainless steel have been made by Mann [11] and Gardner [12], while a number of applications of stainless steel in construction and practical considerations including material selection and fabrication have been provided in [13]. The following subsections provide a brief overview and comparison of the thermal properties of carbon steel and stainless steel, together with a review of existing elevated temperature stainless steel material tests and material modelling techniques.

\subsection{Thermal properties of carbon steel and stainless steel}

The physical and thermal properties of stainless steel differ from those of carbon steel due to the influence of the alloying elements, the principal ones being chromium and nickel. A brief overview of the thermal properties of carbon steel and stainless steel, with an emphasis on the austenitic grades, these being the most widely adopted in construction, is reported herein; a more detailed account is available elsewhere [14].

At elevated temperatures, austenitic stainless steel offers better retention of strength and stiffness than carbon steel as presented in Figs 1 and 2, which are based on the data given in EN 1993-1-2 (2005) [15] and in Euro Inox/SCI Design Manual for Structural Stainless Steel [16]. Strength reduction factors for the most commonly used grade of austenitic stainless steel, 1.4301, are depicted, while stiffness reduction factors are common to all grades. The strength reduction factor $\mathrm{k}_{\mathrm{y}, \theta}$ refers to the ratio of the design strength at elevated temperature $\theta$ (based on the elevated temperature strength at $2 \%$ total strain $\sigma_{t 2.0, \theta}$, which gives rise to reduction factors greater than unity at low temperatures) to that at room temperature (based on the $0.2 \%$ proof stress $\sigma_{0.2}$ ), while the stiffness reduction factor $\mathrm{k}_{\mathrm{E}, \theta}$ represents the ratio of Young's modulus at elevated temperature $\theta$ to that at room temperature.

The thermal conductivity of austenitic stainless steel is distinctly different from that of carbon steel, as shown in Fig. $3[15,16]$. Below $1000^{\circ} \mathrm{C}$ stainless steel exhibits lower thermal conductivity than carbon steel. The specific heat of the two materials is similar (around 550 to $600 \mathrm{~J} / \mathrm{kgK}$ ), with the exception that carbon steel undergoes a phase change at around $723^{\circ} \mathrm{C}$, at which point latent heat effects are evident. The thermal expansion of austenitic 
stainless steel is greater than that of carbon steel, resulting in greater forces being induced into restrained members with increasing temperature. The consequences of this are assessed in [6].

\subsection{Material tests at elevated temperatures for stainless steel}

Material testing at elevated temperatures may be conducted either isothermally or anisothermally. In isothermal (steady-state) testing, the material coupon is heated up to the required test temperature, which is then held constant while the tensile test is performed. In anisothermal (transient) testing, the specimen is stressed to a specified level and then the temperature is gradually increased until failure. The anisothermal testing technique is generally considered to be more representative of actual fire scenarios (where structures endure increasing temperatures as the fire develops), provided the rate of temperature increase employed during testing broadly matches that experienced by structural members in fires.

Early investigations into the mechanical properties of stainless steel at elevated temperatures were carried out in the USA during 1960-70s and were later reported by Hoke [1]. Strength reduction factors $\left(\mathrm{k}_{0.2, \theta}\right.$ and $\left.\mathrm{k}_{\mathrm{u}, \theta}\right)$ and stiffness reduction factors $\left(\mathrm{k}_{\mathrm{E}, \theta}\right)$ for various austenitic and ferritic grades were investigated. The main focus of the research was to study the effects of alloying elements on the material response at elevated temperatures and hence modify the composition of alloys to enhance performance. Typical physical and mechanical properties at elevated temperatures for eight grades of stainless steel were reported in [17]. No further investigations on the performance of stainless steel at elevated temperatures (of the levels experienced in fire) were documented until 1996, since when a number of studies have been performed.

Ala-Outinen [18] reported isothermal tensile tests on both virgin sheet and cold-formed material of austenitic grades 1.4301 and 1.4571 , up to $900^{\circ} \mathrm{C}$ and $950^{\circ} \mathrm{C}$, respectively. Additional anisothermal test results on the same material were provided by Ala-Outinen and Oksanen [3]. The cold-formed material was extracted from cold-rolled structural hollow sections, and would therefore have undergone some degree of cold-work during production [19]. Sakumoto et al. [20] conducted both isothermal and anisothermal elevated temperature material tests on austenitic grades 1.4301 and 1.4401. The test results showed that the 1.4401 
material, which contains higher levels of molybdenum, offered better performance than the 1.4301 material. Zhao [21] reported similar tests on five grades of stainless steel sheet material $-1.4301,1.4401,1.4571,1.4462$ and 1.4003 to assess their elevated temperature properties, while Chen and Young [22] examined material extracted from cold-rolled structural sections of grade 1.4301 and 1.4462 stainless steel; as with the Ala-Outinen and Oksanen [3] cold-formed test material, the material examined by Chen and Young would have experienced a degree of cold-working during forming, and the elevated temperature strength retention characteristics may be expected to differ from those for virgin (annealed) sheet material. Montanari and Zilli [23] conducted anisothermal tests on austenitic grade 1.4541 stainless steel, with material tested in the longitudinal and transverse directions. Latterly, a series of anisothermal tests [24] on sheet material of stainless steel grades 1.4318, 1.4541, 1.4462, 1.4162, 1.4362 and 1.4818 were performed; of these six grades, four, including a recently developed lean duplex grade (1.4162) [25], have not been covered by previous structural fire design guidance.

The elevated temperature response of cold-worked stainless steel was recently investigated [26-28], as part of wider study on the structural usage of such material [29,30]. EN 1993-1-4 (2005) [31] specifies a number of cold-worked levels, which are defined either in terms of minimum yield strength or minimum ultimate tensile strength of the sheet material and are taken from the European material standard for stainless steel, EN 10088-2 (2005) [32]. It should be emphasised that cold-worked stainless steel sheet material is supplied to specified minimum standard values, whereas during cold-forming of sections, an unspecified level of cold-work is experienced, depending primarily on the forming route and section geometry. Predictive formulae for harnessing strength enhancements due to cold-work during section forming have been developed [19] and incorporated into the UK National Annex [33] to EN 1993-1-4. In the recent studies [26-28], the elevated temperature properties of grades 1.4318, 1.4571 and 1.4541 were investigated in the annealed condition and with strength level C850, which designates a minimum ultimate tensile strength of $850 \mathrm{~N} / \mathrm{mm}^{2}$.

\subsection{Elevated temperature material modelling techniques}

A precise understanding of the response of structures to elevated temperatures requires accurate material modelling. EN 1993-1-2 (2005) [15] provides a three stage material model to describe the elevated temperature stress-strain response of carbon steel and a separate two stage model for stainless steel. In the first stage of the carbon steel model, stress is directly 
proportional to strain up to the proportional limit. This is followed by a nonlinear relationship between stress and strain in the second stage up to an effective yield strength and, finally, the third stage comprises a flat plateau up to the limiting strain $\varepsilon u, \theta$. Strain hardening may also be considered with reference to Annex A of EN 1993-1-2. For stainless steel, Annex C of EN 1993-1-2 (2005) provides a nonlinear two stage stress-strain model, as described by Eqs (1) and (2).

$$
\begin{array}{ll}
\sigma=\frac{\mathrm{E} \varepsilon}{1+\mathrm{a} \varepsilon^{\mathrm{b}}} & \text { for } \varepsilon \leq \varepsilon_{\mathrm{t} 0.2, \theta} \\
\sigma=\sigma_{0.2, \theta}-\mathrm{e}+\frac{\mathrm{d}}{\mathrm{c}} \sqrt{\mathrm{c}^{2}-\left(\varepsilon_{\mathrm{u}, \theta}-\varepsilon\right)^{2}} & \text { for } \varepsilon_{\mathrm{t} 0.2, \theta}<\varepsilon \leq \varepsilon_{\mathrm{u}, \theta}
\end{array}
$$

where $\sigma$ and $\varepsilon$ are the engineering stress and strain respectively, E is Young's modulus at room temperature, $\varepsilon_{\mathrm{u}, \theta}$ is the ultimate strain at elevated temperature $\theta, \varepsilon_{t 0.2, \theta}$ is the total strain at the $0.2 \%$ proof stress at elevated temperature $\theta$ and the coefficients a, b, c, $d$ and e are each expressed as functions of elevated temperature properties in EN 1993-1-2. The tangent modulus $E_{0.2}$ at the $0.2 \%$ proof stress, which is required for the determination of some of the coefficients, may be determined from Eqs (3) and (4).

$$
\begin{array}{ll}
\mathrm{E}_{0.2}=\frac{\mathrm{E}\left(1+\mathrm{a} \varepsilon^{\mathrm{b}}-\mathrm{ab} \varepsilon^{\mathrm{b}}\right)}{\left(1+\mathrm{a} \varepsilon^{\mathrm{b}}\right)^{2}} & \text { for } \varepsilon \leq \varepsilon_{\mathrm{t} 0.2, \theta} \\
\mathrm{E}_{0.2}=\frac{\mathrm{d}+\left(\varepsilon_{\mathrm{u}, \theta}-\varepsilon\right)}{\mathrm{c} \sqrt{\mathrm{c}^{2}-\left(\varepsilon_{\mathrm{u}, \theta}-\varepsilon\right)^{2}}} & \text { for } \varepsilon_{\mathrm{t} 0.2, \theta}<\varepsilon \leq \varepsilon_{\mathrm{u}, \theta}
\end{array}
$$

The material model for stainless steel provided in EN 1993-1-2 is complex, and requires the determination of a number of interdependent coefficients that have no clear physical meaning.

An alternative approach to the material modelling of stainless steel at elevated temperatures was proposed by Chen and Young [22], whereby the compound Ramberg-Osgood material model [34,35], which is now widely adopted at room temperature, was recalibrated for 
elevated temperatures. Good agreement was reported between the observed stress-strain behaviour and the compound Ramberg-Osgood formulation when experimental values for the key material parameters were employed. A modified compound Ramberg-Osgood expression, which provides greater accuracy than existing models and utilises the material parameters currently employed for fire design in Eurocode 3, is proposed herein.

\section{Strength and stiffness reduction factors at elevated temperatures}

\subsection{Introduction}

Material properties at elevated temperatures form an essential part of structural fire modelling and design. Guidance on stainless steel material properties at elevated temperature, including strength and stiffness reduction factors and description of the stress-strain response, is provided in EN 1993-1-2 (2005) [15] and in the Euro Inox/SCI Design Manual for Structural Stainless Steel [16]. The key parameters i.e. $0.2 \%$ proof stress $\sigma_{0.2, \theta}$, stress at $2 \%$ total strain $\sigma_{\mathrm{t} 2.0, \theta}$, ultimate stress $\sigma_{\mathrm{u}, \theta}$ and Young's modulus $\mathrm{E}_{\theta}$ at an elevated temperature $\theta$ are typically expressed as a proportion of the corresponding room temperature properties, with the exception of the stress at $2 \%$ total strain, which is generally normalised by the room temperature $0.2 \%$ proof strength, since this is the accepted design strength for general structural calculations and is widely available.

In this section, all available elevated temperature material test results on stainless steel alloys are analysed in order to obtain accurate strength reduction factors $\left(\mathrm{k}_{0.2, \theta}=\sigma_{0.2, \theta} / \sigma_{0.2}\right.$, $\mathrm{k}_{\mathrm{u}, \theta}=\sigma_{\mathrm{u}, \theta} / \sigma_{\mathrm{u}}$ ), a factor $\mathrm{k}_{2 \%, \theta}$ (denoted $\mathrm{g}_{2, \theta}$ the in the Euro Inox/SCI Design Manual [16]) used to determine the elevated temperature strength at $2 \%$ total strain (see Eq. (5)) and stiffness reduction factor $\left(\mathrm{k}_{\mathrm{E}, \theta}=\mathrm{E}_{\theta} / \mathrm{E}\right)$. An additional objective was to extend the range of grades covered by current structural design guidance, while also rationalising the number of strength reduction factors provided to designers by grouping grades that exhibit similar characteristics. A total of eight sets of reduction factors (see Figs 4 and 5) are currently provided for stainless steel compared to a single set for carbon steel; five sets of reduction factors are given in EN 1993-1-2 [15] and seven sets (four of which are the same as the EN 1993-1-2 sets) are given in the Euro Inox/SCI Design Manual for Structural Stainless Steel [16]. A number of sets of reduction factors are appropriate for stainless steel since the elevated temperature properties 
can vary markedly between different grades, but this has to be justified with sufficient test data and balanced against ease of design.

\subsection{Basis for derivation of strength reduction factors}

\subsubsection{Testing techniques}

Elevated temperature material testing may be conducted using isothermal or anisothermal techniques. At high temperatures, above about $400^{\circ} \mathrm{C}$, creep strains become increasingly influential, generally resulting in lower reduction factors being obtained from transient tests than steady state tests. The isothermal and anisothermal tests reported by Ala-Outinen [18] and Ala-Outinen and Oksanen [3], together with those presented by Sakumoto [20], allow a direct comparison between the results obtained for stainless steel from these two testing techniques. With reference to the $0.2 \%$ proof strength, the authors of both of the above studies indeed observed lower reduction factors from anisothermal tests, but at higher strains, the differences were small. Under fire conditions, high strains are tolerable, reflected by frequent use of the strength at $2 \%$ strain for elevated temperature design, and on this basis, Kirby and Preston [36] argued that data derived from either testing technique may be used to predict the behaviour of steel elements in fire.

The rate of testing is also important, and for derived strength reduction factors to be representative, the rate of temperature increase employed during testing should broadly match that experienced by structural members in fires. The rates of temperature increase utilised in the transient tests reviewed herein were between $5^{\circ} \mathrm{C} / \mathrm{min}$ and $10^{\circ} \mathrm{C} / \mathrm{min}$, which approximates the rate of temperature increase in protected steelwork in fire. This is appropriate for structural carbon steel, which is rarely used unprotected, but this is not the case for stainless steel, where use in exposed unprotected structural applications is commonplace, and thus the rate of temperature development is considerably higher and the influence of creep less significant. Strength reduction factors obtained for stainless steel by anisothermal testing at the relatively low temperature development rates reported in the literature may therefore be expected to be conservative for practical fire situations.

Regarding the testing techniques used for establishing existing design guidance, the strength reduction factors provided for carbon steel in EN 1993-1-2 [15] were developed on the basis of anisothermal testing, while those provided for stainless steel $[15,16]$ were derived on the basis of both isothermal and anisothermal testing. 
Given the above described observations and to maintain consistency with the manner in which current strength reduction factors $[15,16]$ were obtained, while also maximising the usage of the limited available data for stainless steel, both isothermal and anisothermal test results will be considered for the derivation of strength reduction factors in this study.

\subsubsection{Influence of cold-work}

Stainless steel exhibits a pronounced response to cold-work, and hence the level of plastic deformation experienced during production has a strong bearing on the material response of the final sections. The influence of three processes is considered: (1) general sheet forming, (2) sheet forming to a specified cold-worked level and (3) section forming.

(1) Sheet material may be either hot-rolled or cold-rolled, with cold-rolling being used for thinner gauges. There are a number of delivery conditions for each, but the minimum specified $0.2 \%$ proof strength for any given grade is similar [32] and thus no distinction will be made between rolling methods in this study.

(2) Sheet material may also be intentionally cold-worked to a specified strength level. Since the strength class will be known and specified to a standard level [32], for example 1.4318 C850, then differences in elevated temperature material response can be systematically accounted for.

(3) Finally, cold-work may be induced during section forming [19]. Elevated temperature test data on material extracted from cold-formed tubular sections have been presented by AlaOutinen [18] and Chen and Young [22]. These data are valuable, since they demonstrate (see Fig. 6 where the results of Ala-Outinen [18] are shown) that strength enhancements existing at room temperature as a result of cold-work are maintained at moderate fire temperatures (up to about $700^{\circ} \mathrm{C}$ ), but beyond this temperature the beneficial effect of cold-work is lost. Therefore, if the cold-work due to section forming were to be utilised, it would be unconservative to apply the strength reduction factors for annealed material to the enhanced strength of the section. Conversely, if this strength enhancement is not exploited, then the strength reduction factors for annealed sheet material may be safely applied to cold-formed sections. This is discussed further in Section 3.6. 


\subsection{Reduction factors for $\mathbf{0 . 2 \%}$ proof strength and ultimate tensile strength}

Test data providing $0.2 \%$ proof strength reduction factors $\left(\mathrm{k}_{0.2, \theta}=\sigma_{0.2, \theta} / \sigma_{0.2}\right)$ for twelve grades of stainless steel are shown in Fig. 7, where a distinction is made between the method of testing - isothermal and anisothermal. Similar graphs for ultimate strength reduction factors $\left(\mathrm{k}_{\mathrm{u}}=\sigma_{\mathrm{u}, \theta} / \sigma_{\mathrm{u}}\right)$ are shown in Fig. 8. To both sets of graphs, the existing reduction factors (where provided in either EN 1993-1-2 or the SCI/ Euro Inox Design Manual), together with the proposed reduction factors have been added. In some references, reduction factors were presented on the basis of a combination of isothermal and anisothermal test data, without providing individual results; such data sets have been referred to as combined test data in Figs 7 and 8. Note that test data is presented for annealed (virgin) sheet material and sheet material that has undergone cold-work to a specified level only, while material extracted from cold-formed sections has been excluded, as discussed in Section 3.2.

Isothermal and anisothermal tests have been conducted on cold-worked stainless steel material [26,27], but not reported in sufficient detail for the individual results to be extracted and examined. The experimental data were, however, analysed by Zhao and Blanguernon [28], who observed little variation between the results obtained from the two testing methods, and proposed reduction factors for grades 1.4318 C850 and 1.4571 C850, which have been adopted in the SCI/Euro Inox Design Manual [16] and are also included in the present work.

The grades of stainless steel considered and the corresponding sources of test data are as follows: Austenitic grades 1.4301 [1,3,17,21], 1.4318 [24,26,27], 1.4818 [24], 1.4401/4 [1,17,21], 1.4571 [18,21] and 1.4541 [23,24,26]; duplex grades 1.4462 [21,24], 1.4162 [24] and 1.4362 [24]; ferritic grade 1.4003 [21]; and cold-worked austenitic grades 1.4318-C850 [27] and 1.4571-C850 [26,27].

The presented stainless steel test data reveals, as noted by Kirby and Preston [36], a larger difference between the results of isothermal and anisothermal testing at low strain levels (i.e. the $0.2 \%$ proof strength) than at higher strain levels; in fact, the reduction factors for ultimate tensile strength appear essentially independent of the testing technique. The disparity between isothermal and anisothermal test results at low strains would be expected to reduce if a higher rate of temperature development, more suited to exposed stainless steel, were to be employed 
in the anisothermal tests. As described in Section 3.2, the proposed reduction factors are based on the mean of all isothermal and anisothermal test data available for each grade; mean reduction factors are appropriate since they are applied to characteristic material strengths, provided as minimum specified values in the material standard EN 10088-2. The proposed $0.2 \%$ proof strength and ultimate tensile strength reduction factors for the twelve investigated grades of stainless steel are presented in Tables 1 and 2, respectively.

Following further analysis, it is proposed that the twelve sets of reduction factors given above be rationalised to eight sets - three sets of reduction factors for the austenitic grades, two sets for duplex stainless steels, one set for ferritic stainless steel (grade 1.4003) and two further sets for each of the cold-worked grades.

The three groups of austenitic stainless steel are: austenitic I (1.4301, 1.4318 and 1.4818), austenitic II (1.4401/4 and 1.4541) for more highly alloyed or stabilised grades and austenitic III (1.4571), this stabilised grade being treated separately due to its superior elevated temperature performance. Grade 1.4818 is rarely used in construction and is not covered by existing structural design guidance, but has been included in the austenitic I group since it is a variant of 1.4301 with increased silicon and nitrogen content. The test data for this grade have not been used for the determination of its group's reduction factors, but its performance is marginally better than 1.4301 and hence the austenitic I reduction factors may be safely applied. The two groups of duplex stainless steel are duplex I (1.4362) and, with higher nitrogen content, duplex II (1.4462 and 1.4162).

The resulting strength reduction factors, derived on the basis of the mean reduction factors of the grouped grades, are presented in Tables 4 and 5 . The behaviour of the cold-worked grades is such that they do not fall naturally within the proposed groups; hence, the individual reduction factors for grades 1.4318 C850 and 1.4571 C850 (see Table 3) should be used.

\subsection{Reduction factors for stress at $2 \%$ total strain}

For stainless steel in fire, the material strength at $2 \%$ total strain $\sigma_{t 2.0, \theta}$ may be employed in the design of some structural elements (e.g. tension and bending members). This reflects the allowance for greater deformations in fire and enables higher member strengths to be developed. The strength at $2 \%$ strain is therefore an important parameter for fire design. 
Unlike the elevated temperature $0.2 \%$ proof strength $\sigma_{0.2, \theta}$ and ultimate strength $\sigma_{u, \theta}$ discussed in Section 3.1, which are calculated directly on the basis of reduction factors (multiplied by the corresponding room temperature strengths), the elevated temperature strength at 2\% total strain $\sigma_{\mathrm{t} 2.0, \theta}$ is determined in EN 1993-1-2 [15] by a different approach, as described by Eq. (5). Essentially, the strength at $2 \%$ strain is defined as the $0.2 \%$ proof strength plus a proportion of the difference between the $0.2 \%$ proof strength and ultimate strength, which themselves bound the value of the strength at $2 \%$ strain. This proportion is defined by the $\mathrm{k}_{2.0 \%, \theta}$ factor.

$$
\sigma_{\mathrm{t} 2.0, \theta}=\sigma_{0.2, \theta}+\mathrm{k} 2.0 \%, \theta\left(\sigma_{\mathrm{u}, \theta}-\sigma_{0.2, \theta}\right)
$$

Based on the assembled set of tests, the derived values of $\mathrm{k}_{2.0 \%, \theta}$ for the grades of stainless steel considered are presented in Table 3, while the values corresponding to the groups of grades described in Section 3.3 are given in Table 6 . Where there are insufficient test data to enable the calculation of $\mathrm{k}_{2} \%, \theta$ values $(1.4401 / 4,1.4571$ and 1.4003$)$, it is proposed that the current values given in EN 1993-1-2 or the Euro Inox/ SCI Design Manual be retained, and these are included in Tables 3 and 6.

\subsection{Reduction factors for Young's modulus}

EN 1993-1-2 [15] and the SCI/ Euro Inox Design Manual [16] currently provide a single set of reduction factors for Young's modulus at elevated temperatures to cover all grades of stainless steel. Available experimental data [1,3,17,18,21-23,26], derived from both isothermal and anisothermal tests, have been gathered and plotted in Fig. 9 to assess the appropriateness of these provisions. The data exhibits considerable scatter; an observation that has been made by a number of authors. Together with a range of possible sources of experimental error [37], the low proportional limit of stainless steel presents a further difficulty in accurately assessing the Young's modulus [3]. In addition to the reduction factors given in EN 1993-1-2 [15] and the SCI/ Euro Inox Design Manual [16], expressions to predict the reduction in Young's modulus as a function of temperature have also been proposed by Ala-Outinen and Oksanen [3] and Chen and Young [22] - these have been added to Fig. 9. The proposal of Chen and Young provides a lower bound to the majority of the data set, but is rather conservative and does not effectively exploit the elevated temperature stiffness retention qualities of the material. The proposal of Ala-Outinen and 
Oksanen [3] follows a similar path to the reduction factors given in EN 1993-1-2 and the SCI/ Euro Inox Design Manual; both also follow the general trend of the test results, though appear to lie above the mean of the collated data for moderate fire temperatures. However, given the uncertainties and scatter of the test data, further investigation is required and it is recommended that the current codified values be maintained.

\subsection{Reduction factors for cold-formed sections}

Cold-formed sections undergo strength enhancements during the section forming process. The level of strength enhancement, for which predictive models have been developed [19], depends on a number of factors, including the strain hardening characteristics of the material and the geometry of the cross-section. By examining the results from tests on sheet material and material from cold-formed sections, it is possible to compare their relative elevated temperature response. Such data exist for grades 1.4301 and 1.4571 stainless steel [3,18,22]. Analysis of the results reveals that the $0.2 \%$ proof strength reduction factors for cold-formed material at temperatures of $800^{\circ} \mathrm{C}$ and above are about $80 \%$ of those for sheet material. Hence, it is proposed that, if the strength enhancements associated with section forming are utilised in design, then the $0.2 \%$ proof strength reduction factors for $800^{\circ} \mathrm{C}$ and above should be reduced by $20 \%$ in relation to those used for sheet material (i.e. k0.2, $\theta$ for cold-formed material $=0.8 \times \mathrm{k}_{0.2, \theta}$ for sheet material, for which the values are given in Tables 1 and 4 ).

From the same sources it may be observed that ultimate tensile strength and reduction factors for ultimate tensile strength at elevated temperatures are less sensitive to the effects of coldwork; thus, it is proposed that the same ultimate strength reduction factors may be applied to both sheet and cold-formed material. (i.e. $\mathrm{k} u, \theta_{\mathrm{\theta}}$ for cold-formed material $=\mathrm{k}_{\mathrm{u}, \theta}$ for sheet material, for which the values are given in Tables 2 and 5).

\section{Material modelling}

The revised reduction factors proposed in Section 3 provide more accurate prediction of discrete features of the elevated temperature material stress-strain response of stainless steel (i.e. Young's modulus, $0.2 \%$ proof strength, strength at $2 \%$ total strain and ultimate strength). In this section, proposals are made for the continuous prediction of the stress-strain response 
by means of a modified compound Ramberg-Osgood material model. The predicted stressstrain curves are then compared to those obtained experimentally. The basis for the proposed elevated temperature stress-strain curves comes from room temperature material modelling, which is briefly reviewed.

\subsection{Material modelling at room temperature}

At room temperature, stainless steel exhibits a rounded stress-strain response with no sharply defined yield point, which is in contrast to the well defined yield point and characteristic yield plateau of carbon steel. At elevated temperatures, the yield point of carbon steel tends to be less pronounced and the stress-strain curve becomes more rounded, whilst the basic form of the stress-strain of stainless steel remains similar to that at room temperature. The origins of many of the recently proposed material models for stainless steel lie in the early work of Ramberg and Osgood [38]. In 1943, the widely used three-parameter RambergOsgood model was proposed to describe the nonlinear behaviour of aluminium. This was later modified by Hill [39] resulting in the familiar expression of Eq. (6).

$$
\varepsilon=\frac{\sigma}{\mathrm{E}}+0.002\left(\frac{\sigma}{\sigma_{0.2}}\right)^{\mathrm{n}}
$$

where $\mathrm{n}$ is the exponential coefficient to take account of the nonlinearity. The basic Ramberg-Osgood model (Eq. (6)) may also be applied to modelling of stainless steel stressstrain behaviour, but becomes inaccurate beyond the $0.2 \%$ proof stress, as illustrated in Fig. 10. This observation led to the proposal [34] and modification and development of [35,4042] the two-stage compound Ramberg-Osgood material model. The initial concept of the two-stage model was that the basic Ramberg-Osgood expression was adopted up to the $0.2 \%$ proof stress, and beyond the $0.2 \%$ proof stress and up to ultimate stress, a second RambergOsgood curve was used. The origin of the second curve was defined at the $0.2 \%$ proof stress, and continuity of magnitude and gradient was ensured at the transition point. A modified version of this model, whereby the second Ramberg-Osgood curve passed through the $1.0 \%$ proof stress instead of the ultimate stress was proposed [40,41]. This model, represented by Eqs (7) and (8), provides greater accuracy at strains associated with common structural applications, requires one less material parameter and may be applied to the description of compressive as well as tensile material behaviour. 


$$
\begin{array}{ll}
\varepsilon=\frac{\sigma}{\mathrm{E}}+0.002\left(\frac{\sigma}{\sigma_{0.2}}\right)^{\mathrm{n}} & \text { for } \sigma \leq \sigma_{0.2} \\
\varepsilon=\frac{\sigma-\sigma_{0.2}}{\mathrm{E}_{0.2}}+\left(\varepsilon_{\mathrm{t} 1.0}-\varepsilon_{\mathrm{t} 0.2}-\frac{\sigma_{1.0}-\sigma_{0.2}}{\mathrm{E}_{0.2}}\right)\left(\frac{\sigma-\sigma_{0.2}}{\sigma_{1.0}-\sigma_{0.2}}\right)^{\mathrm{n}_{0.2,1.0}^{\prime}}+\varepsilon_{\mathrm{t} 0.2} & \text { for } \sigma_{\mathrm{u}}>\sigma>\sigma_{0.2}
\end{array}
$$

where $\sigma_{0.2}$ and $\sigma_{1.0}$ are the $0.2 \%$ and $1 \%$ proof stresses respectively, $\sigma_{u}$ is the ultimate tensile strength, $\varepsilon_{t 0.2}$ and $\varepsilon t 1.0$ are the total strains corresponding to $\sigma_{0.2}$ and $\sigma_{1.0}, E_{0.2}$ is the tangent modulus at $\sigma_{0.2}$ and $n$ and $n_{0.2,1.0}$ are the exponential constants to define the degree of the material nonlinearity. A more detailed review of previous material models, together with an assessment of their relative advantages and limitations, has been performed elsewhere [43].

Table 7 lists the proposed compound Ramberg-Osgood coefficients $n$ and n'0.2,1.0 for different stainless steel grades at room temperature, which were obtained by analysing all available material test results [44].

\subsection{Material modelling at elevated temperatures}

For design, accurate representation of the elevated temperature material stress-strain response may generally not be necessary. However, for detailed insight into the response of stainless steel structures in fire, accurate material modelling is essential, and is sought herein. The proposed material model for stainless steel at elevated temperatures is based on the compound Ramberg-Osgood concept, and is thus of similar form to Eqs (7) and (8). However, rather than employing the $0.2 \%$ and $1 \%$ proof strengths (which are commonly available for room temperature design) as the points though which the Ramberg-Osgood passes, the proposed model utilises the material strength parameters employed for fire design in Eurocode 3, namely the elevated temperature $0.2 \%$ proof strength $\sigma_{0.2, \theta}$ and the strength at $2 \%$ total strain $\sigma_{t 2.0, \theta}$. The resulting model is given by Eqs (9) and (10), and illustrated in Fig. 11.

$$
\varepsilon=\frac{\sigma}{\mathrm{E}_{\theta}}+0.002\left(\frac{\sigma}{\sigma_{0.2, \theta}}\right)^{\mathrm{n}_{\theta}} \quad \text { for } \sigma \leq \sigma_{0.2, \theta}
$$




$$
\varepsilon=\frac{\sigma-\sigma_{0.2, \theta}}{\mathrm{E}_{0.2, \theta}}+\left(0.02-\varepsilon_{\mathrm{t} 0.2, \theta}-\frac{\sigma_{\mathrm{t} 2.0, \theta}-\sigma_{0.2, \theta}}{\mathrm{E}_{0.2, \theta}}\right)\left(\frac{\sigma-\sigma_{0.2, \theta}}{\sigma_{\mathrm{t} 2.0, \theta}-\sigma_{0.2, \theta}}\right)^{\mathrm{n}_{\theta}^{\prime}}+\varepsilon_{\mathrm{t} 0.2, \theta} \text { for } \sigma_{\mathrm{u}, \theta}>\sigma>\sigma_{0.2, \theta}
$$

where $\sigma$ and $\varepsilon$ are the engineering stress and strain, respectively, $\sigma_{0.2, \theta}$ is the $0.2 \%$ proof stress at temperature $\theta, \sigma_{\mathrm{u}, \theta}$ is the ultimate tensile strength at temperature $\theta, \sigma_{\mathrm{t} 2.0, \theta}$ is the stress at $2.0 \%$ total strain at temperature $\theta, \varepsilon_{t 0.2, \theta}$ is the total strain corresponding to $\sigma_{0.2, \theta}, \mathrm{E}_{\theta}$ and $\mathrm{E}_{0.2, \theta}$ are the material's Young's modulus and tangent modulus at $\sigma_{0.2}$ respectively at temperature $\theta$ and $n_{\theta}$ and $n^{\prime}{ }_{\theta}$ are the exponential coefficients to define the degree of material nonlinearity at temperature $\theta$. In Section 5 , values for the required coefficients are proposed for the different grades under consideration and comparisons between predicted and observed material behaviour are made.

\section{Compound Ramberg-Osgood coefficients at elevated temperatures}

The proposed material model for stainless steel at elevated temperatures as given by Eqs (9) and (10) requires determination of the elevated temperature $0.2 \%$ proof stress $\sigma_{0.2, \theta}$, the elevated temperature stress at $2 \%$ total strain $\sigma_{\mathrm{t} 2.0, \theta}$, the elevated temperature Young's modulus $E_{\theta}$ and the coefficients $n_{\theta}$ and $n_{\theta}^{\prime}$. The first three parameters may either be determined directly from tests or by applying the reduction factors described in Section 3. All available complete stainless steel stress-strain curves have been analysed to obtain appropriate values for the coefficients $n_{\theta}$ and $n_{\theta}^{\prime}$ for at elevated temperatures - resulting values for austenitic grades 1.4301 and 1.4401/4 are presented in Table 8; these values may be assumed to be representative of other austenitic grades. Figs 12 and 13 compare the proposed material model with test results [21] for grades 1.4301 and 1.4404. Fig. 14 compares the Eurocode model for stainless steel with the test stress-strain curves shown in Fig. 12, and clearly demonstrates the improved accuracy of the proposed material model over the more complex model provided in EN 1993-1-2 (2005). 


\section{Conclusions}

Accurate knowledge of material properties at elevated temperatures represents an essential part of structural fire modelling and design. This paper focuses on the prediction and modelling of the elevated temperature stress-strain response of stainless steel alloys. All available test data, much of which have been recently generated, have been analysed and revised strength and stiffness reduction factors at elevated temperatures for a range of grades of stainless steel have been proposed on a consistent basis. Although a total of thirteen sets of strength reduction factors have been determined, it has been proposed that these be rationalised to ten sets on the basis of grouping grades that exhibit similar elevated temperature properties. In addition to more accurate prediction of discrete features of the elevated temperature material stress-strain response of stainless steel (i.e. strength and stiffness reduction factors), a material model for the continuous prediction of the stress-strain response by means of a modified compound Ramberg-Osgood formulation has also been proposed. The proposed model is less complex than the current provisions of EN 1993-1-2, more accurate when compared to test results, and the model parameters have a clear physical significance.

\section{Acknowledgements}

The authors would like to thank Outokumpu for the provision of test data and technical input, as well as Nancy Baddoo of the Steel Construction Institute and Alan Harrison of the British Stainless Steel Association for technical advice. The authors also would like to acknowledge the Basque Government (Department of Education, Universities and Research) for the financial support given under the overseas post-doctoral development scheme in 2009.

\section{References}

[1] Hoke, J. H. (1977). Mechanical Properties of Stainless Steels at Elevated Temperatures. Handbook of Stainless Steels - Chapter 21, McGraw-Hill. 
[2] Davies, C. M., (2009). Predicting Creep Crack Initiation in Austenitic and Ferritic Steels using the Creep Toughness Parameter and Time Dependent Failure Assessment Diagram. Fatigue and Fracture of Engineering Materials and Structures. 32(10), 820-836.

[3] Ala-Outinen, T. and Oksanen, T. (1997). Stainless steel compression members exposed to fire. VTT Research Notes 1864, Espoo, Finland.

[4] Ala-Outinen, T. (1999). Fire resistance of stainless steel structures. Proceedings of the Second European Conference on Steel Structures (Eurosteel 1999). Prague, Czech Republic, 26th-29th May, 1999. 165-168.

[5] Gardner, L. and Baddoo, N. (2006). Fire testing and design of stainless steel structures. Journal of Constructional Steel Research. 62(6), 532-543.

[6] Gardner, L. (2007). Stainless steel structures in fire. Proceedings of the Institution of Civil Engineers - Structures and Buildings. 160(3), 129-138.

[7] Vila Real, P.M.M., Lopes, N., Simões da Silva, L. and Franssen, J.-M. (2008). Lateraltorsional buckling of stainless steel I-beams in case of fire. Journal of Constructional Steel Research. 64(11), 1302-1309.

[8] Uppfeldt, B., Ala Outinen, T. and Veljkovic, M. (2008). A design model for stainless steel box columns in fire. Journal of Constructional Steel Research, 64(11), 1294-1301.

[9] Wang, Y. C. (2002). Steel and composite structures - behaviour and design for fire safety. Spon Press.

[10] Buchanan, A. H. (2001). Structural design for fire safety. John Wiley and Sons Ltd.

[11] Mann, A. P. (1993). The structural use of stainless steel. The Structural Engineer. 71(4), 60-69.

[12] Gardner, L. (2005). The use of stainless steel in structures. Progress in Structural Engineering and Materials. 7(2). 45-55. 
[13] Baddoo, N. R., Burgan, R. and Ogden, R. Architects’ Guide to Stainless Steel. (1997). SCI-P-179. The Steel Construction Institute, UK.

[14] Gardner, L. and Ng, K. T. (2006). Temperature development in structural stainless steel sections exposed to fire. Fire Safety Journal. 41(3), 185-203.

[15] EN 1993-1-2. (2005). Eurocode 3: Design of steel structures - Part 1.2: General rules Structural fire design. CEN.

[16] Euro Inox/ SCI (2006). Design Manual for Structural Stainless Steel. Third Edition. Euro Inox and the Steel Construction Institute. Building series, Volume 3.

[17] AISI (1979). High-Temperature Characteristics of Stainless Steels, Handbook Series No. 9004, American Iron and Steel Institute/ Nickel Institute.

[18] Ala-Outinen, T. (1996). Fire resistance of austenitic stainless steels Polarit 725 (EN 1.4301) and Polarit 761 (EN 1.4571). VTT Research Notes 1760. Espoo, Finland.

[19] Cruise, R. B. and Gardner, L. (2008). Strength enhancements induced during cold forming of stainless steel sections. Journal of Constructional Steel Research. 64(11), 13101316.

[20] Sakumoto, Y., Nakazato, T. and Matsuzaki, A. (1996). High-temperature properties of stainless steel for building structures. Journal of Structural Engineering, ASCE. 122(4), 399406.

[21] Zhao, B. (2000). Work Package 5.1: Material behaviour at elevated temperatures. ECSC project 'Development of the use of stainless steel in construction'. Contract No. 7210 SA/842. CTICM, France.

[22] Chen, J. and Young, B. (2006). Stress-strain curves for stainless steel at elevated temperatures. Engineering Structures. 28(2), 229-239. 
[23] Montanari, A. and Zilli, G. (2007). Work Package 4: Properties at elevated temperatures. RFCS project 'Stainless Steel in Fire'. Contract No. RFSR-CT-2004-00048. CSM, Italy.

[24] Outokumpu (2008). Anisothermal tests on stainless steel grades. Confidential Outokumpu report.

[25] Theofanous, M. and Gardner, L. (submitted). Testing and numerical modelling of lean duplex stainless steel hollow section columns. Engineering Structures.

[26] Ala-Outinen, T., Viherma, R. and Nilimaa, H., (2003). Work Package 6: Elevated Temperature Properties - Isothermal material tests. ECSC project 'Structural design of cold worked austenitic stainless steel'. Contract No. 7210-PR-318. VTT Building and Transport, Finland.

[27] Conrad, F. (2003). Work Package 6: Elevated Temperature Properties - Anisothermal material tests. ECSC project 'Structural design of cold worked austenitic stainless steel'. Contract No. 7210-PR-318. Ugine \& Alz - Arcelor group.

[28] Zhao, B and Blanguernon, A. (2004). Work Package 6: Elevated Temperature Properties - Material model for cold formed stainless steel and experimental results of structural members under standard fire. ECSC project 'Structural design of cold worked austenitic stainless steel'. Contract No. 7210-PR-318. CTICM, France.

[29] Baddoo, N. R and Chinien, V. L. (2006). Structural design of cold worked austenitic stainless steel. European Commission. Directorate-General for Research.

[30] Gardner, L., Talja, A. and Baddoo, N. R. (2006). Structural design of high strength austenitic stainless steel. Thin-Walled Structures. 44(5), 517-528.

[31] EN 1993-1-4 (2006) Eurocode 3. Design of Steel Structures: Part 1-4: General rules Supplementary rules for stainless steels. CEN.

[32] EN 10088-2. (2005). Stainless steels - Part 2: Technical delivery conditions for sheet/plate and strip for general purposes. CEN. 
[33] UK NA to EN 1993-1-4. (2008). UK National Annex to Eurocode 3. Design of Steel Structures: Part 1-4: General rules - Supplementary rules for stainless steels. BSI.

[34] Mirambell, E. and Real, E. (2000). On the calculation of deflections in structural stainless steel beams: an experimental and numerical investigation. Journal of Constructional Steel Research. 54(1), 109-133.

[35] Rasmussen, K. J. R. (2003). Full-Range Stress-Strain Curves for Stainless Steel Alloys. Journal of Constructional Steel Research. 59(1), 47-61.

[36] Kirby, B. R. and Preston, R. R. (1988). High Temperature Properties of Hot-rolled, Structural Steels for Use in Fire Engineering Design Studies. Fire Safety Journal. 13(1), 2737.

[37] Cooke, G. M. E. (1988). An Introduction to the Mechanical Properties of Structural Steel at Elevated Temperatures. Fire Safety Journal. 13(1), 45-54.

[38] Ramberg, W. and Osgood, W. R. (1943). Description of stress-strain curves by three parameters. Technical Note No. 902, National Advisory Committee for Aeronautics. Washington, D.C.

[39] Hill, H. N. (1944). Determination of stress-strain relations from the offset yield strength values. Technical Note No. 927, National Advisory Committee for Aeronautics, Washington, D.C.

[40] Gardner, L. and Nethercot, D. A. (2004). Experiments on stainless steel hollow sections - Part 1: Material and cross-sectional behaviour. Journal of Constructional Steel Research. 60(9), 1291-1318.

[41] Gardner, L. and Ashraf, M. (2006). Structural design for non-linear metallic materials. Engineering Structures. 28(6), 926-934. 
[42] Abdella, K. (2007). An explicit stress formulation for stainless steel applicable in tension and compression. Journal of Constructional Steel Research. 63(3), 326-331.

[43] Ashraf, M. (2006). Structural stainless steel design: Resistance based on deformation capacity. PhD Thesis. Department of Civil and Environmental Engineering, Imperial College London, UK.

[44] Ashraf, M., Gardner, L. and Nethercot, D. A. (2006). Finite element modelling of structural stainless steel cross-sections. Thin-walled Structures. 44(10), 1048-1062. 


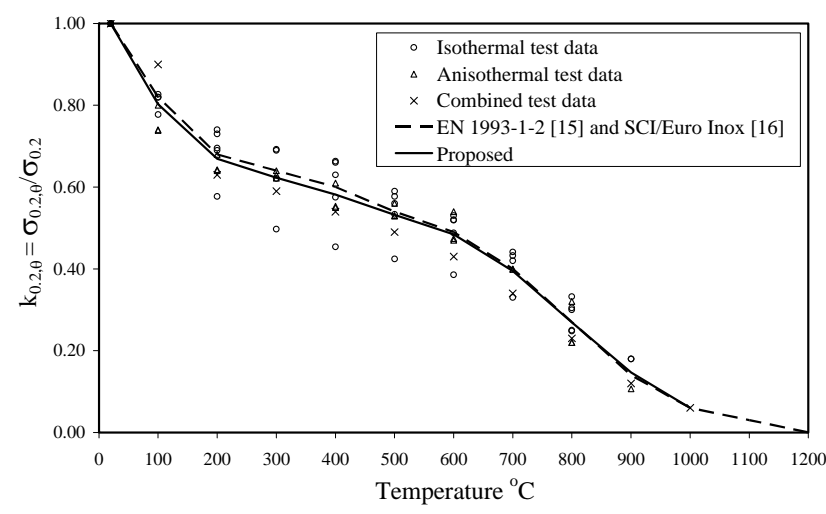

(a) Grade 1.4301

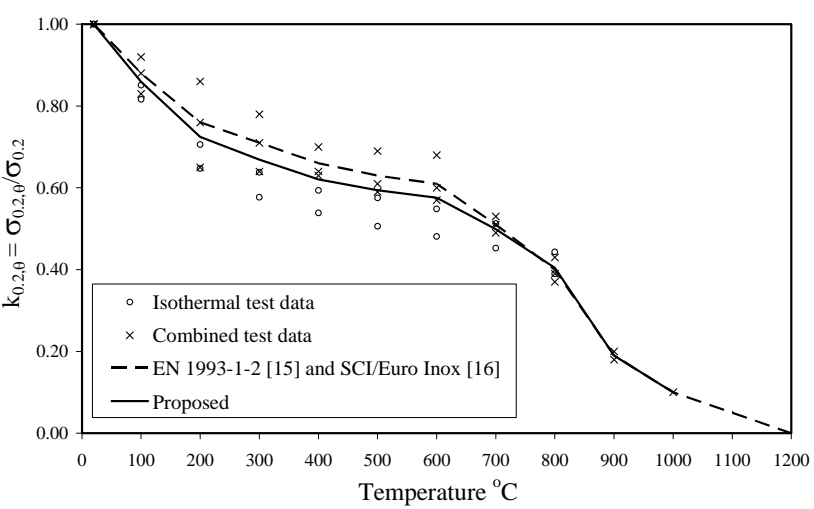

(c) Grade 1.4401/4

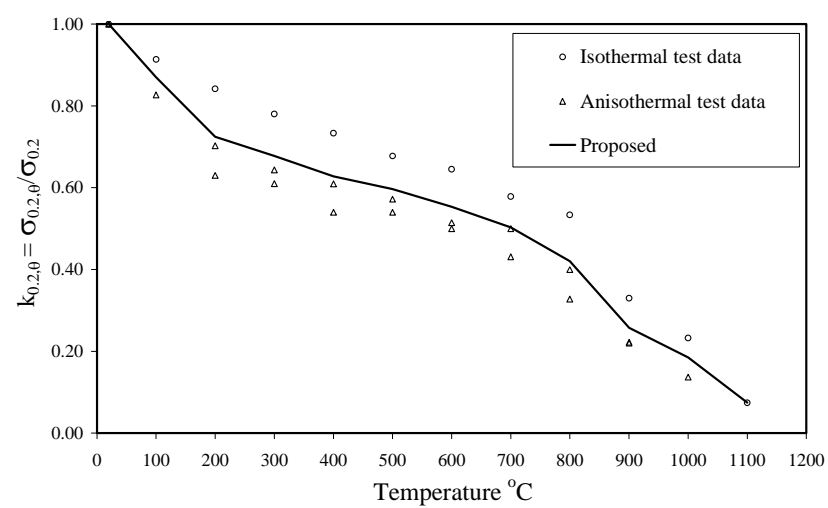

(e) Grade 1.4541

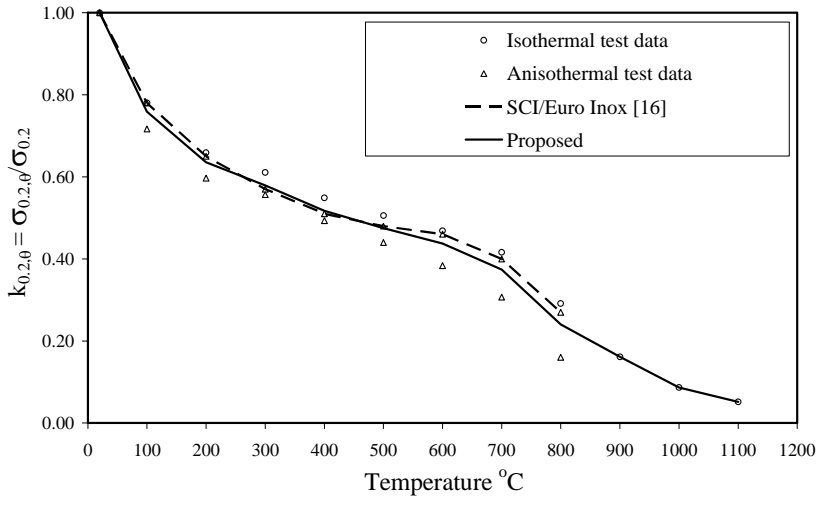

(b) Grade 1.4318

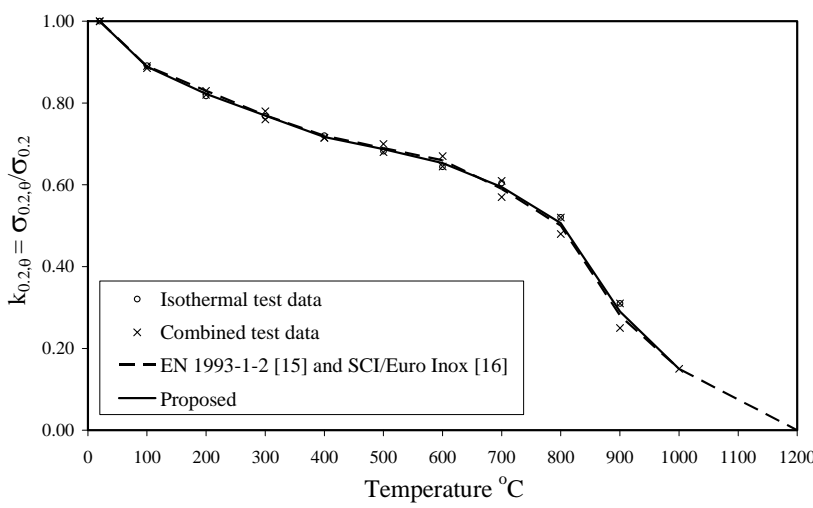

(d) Grade 1.4571

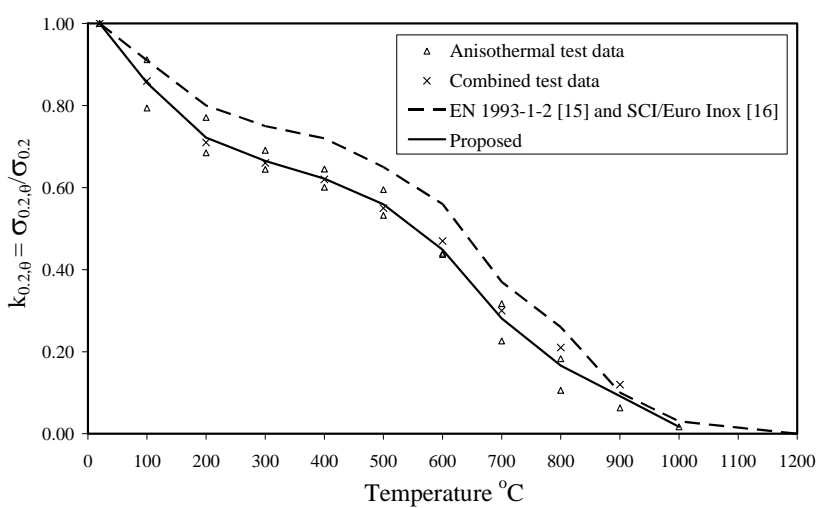

(f) Grade 1.4462 


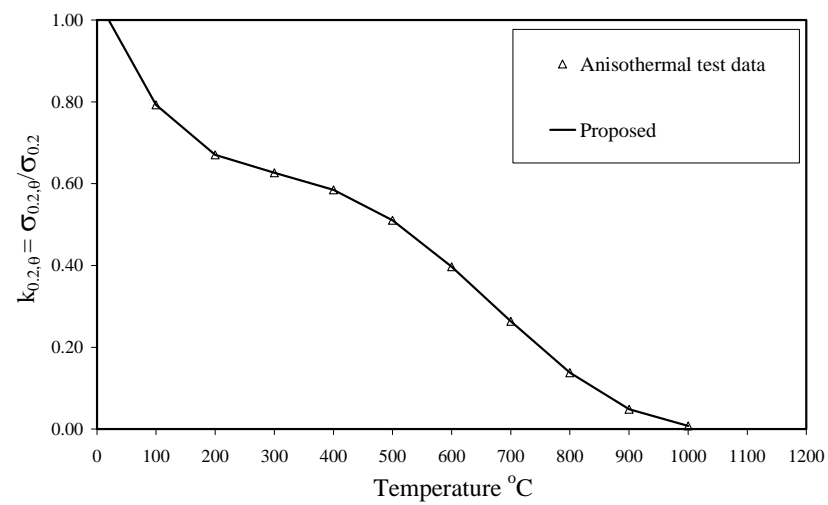

(g) Grade 1.4162 (LDX 2101)

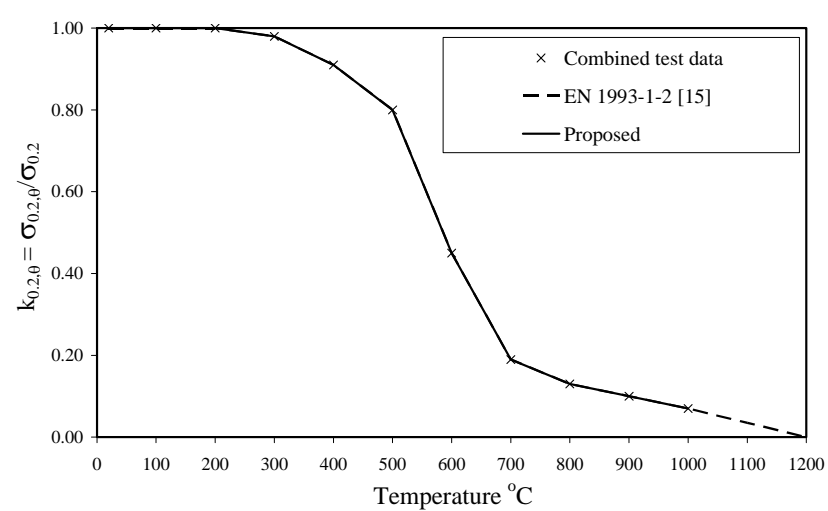

(i) Grade 1.4003

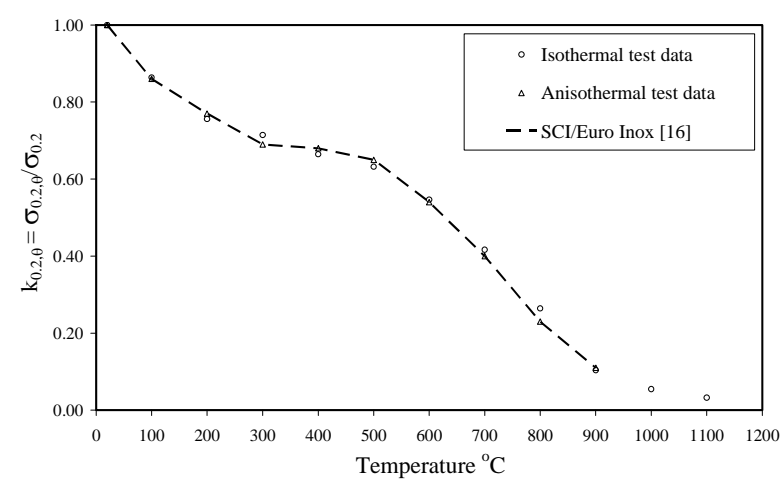

(k) Grade 1.4318 C850

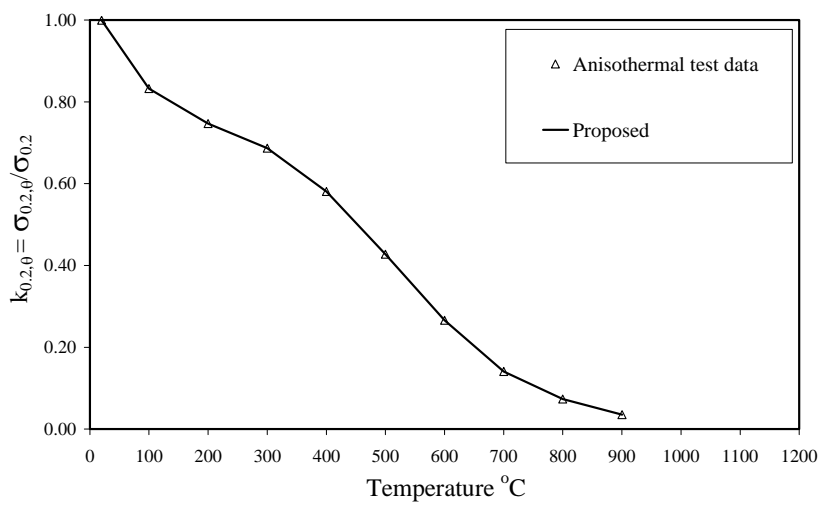

(h) Grade 1.4362

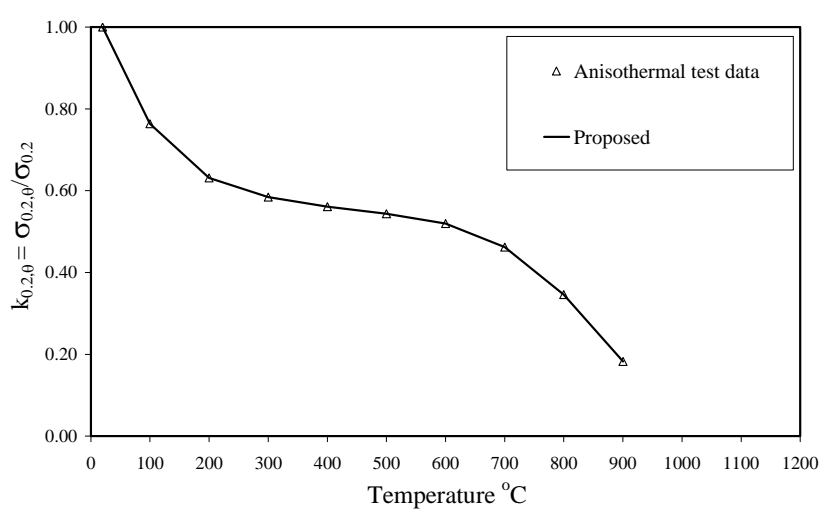

(j) Grade 1.4818

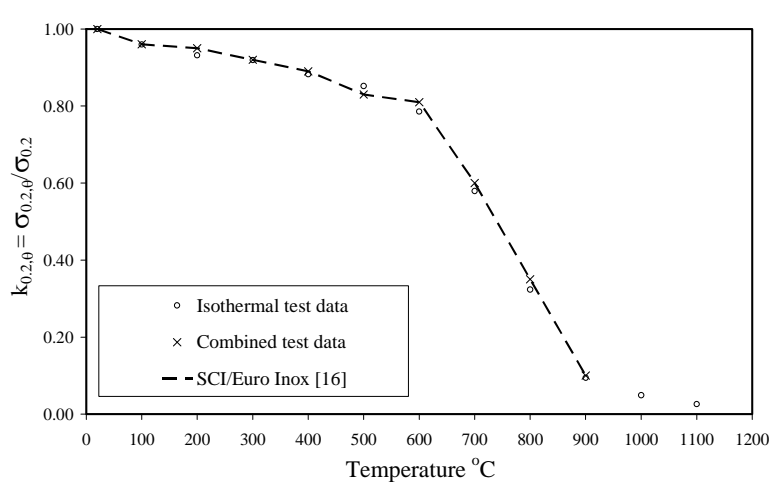

(l) Grade 1.4571 C850

Fig. 7: Proposed $0.2 \%$ strength reduction factors $\mathrm{k}_{0.2, \theta}$ for different stainless steel grades. 


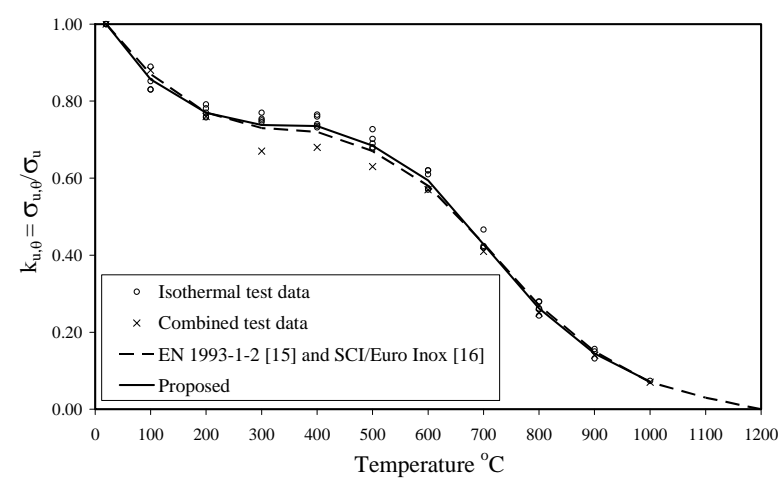

(a) Grade 1.4301

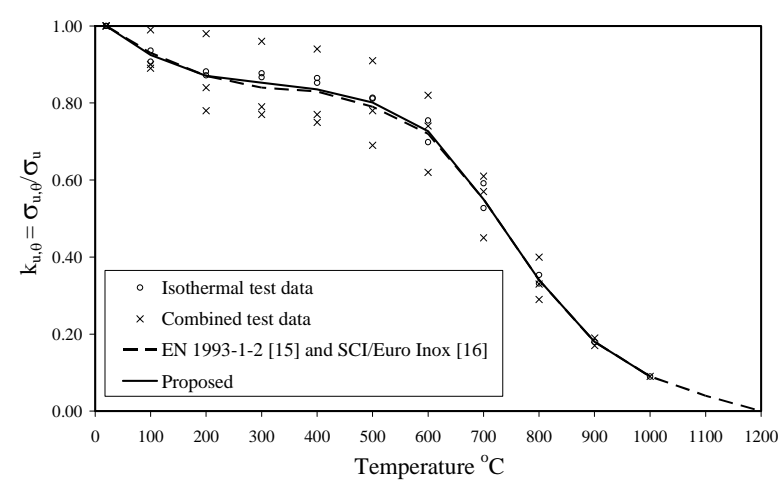

(c) Grade 1.4401/4

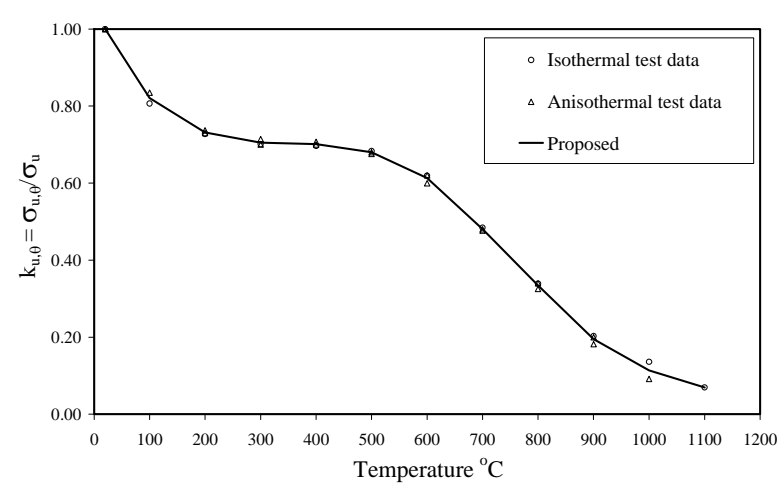

(e) Grade 1.4541

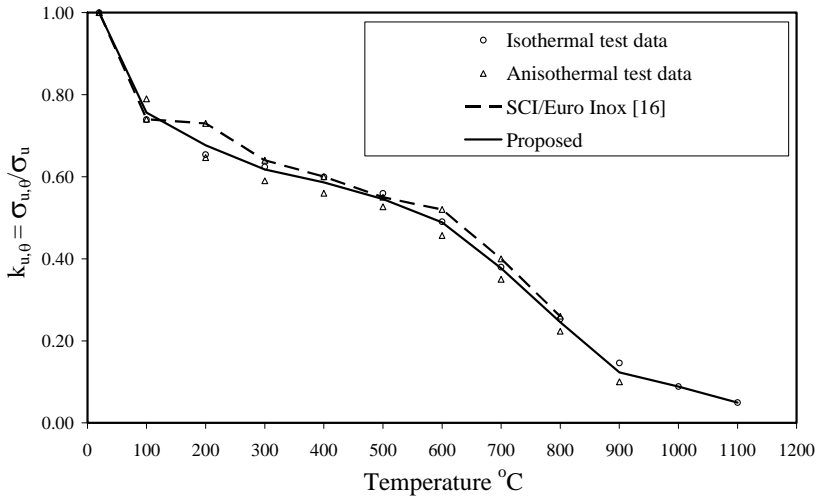

(b) Grade 1.4318

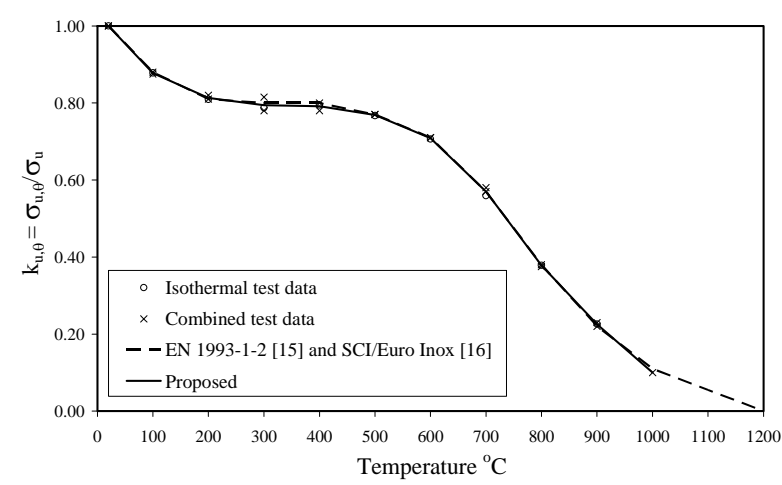

(d) Grade 1.4571

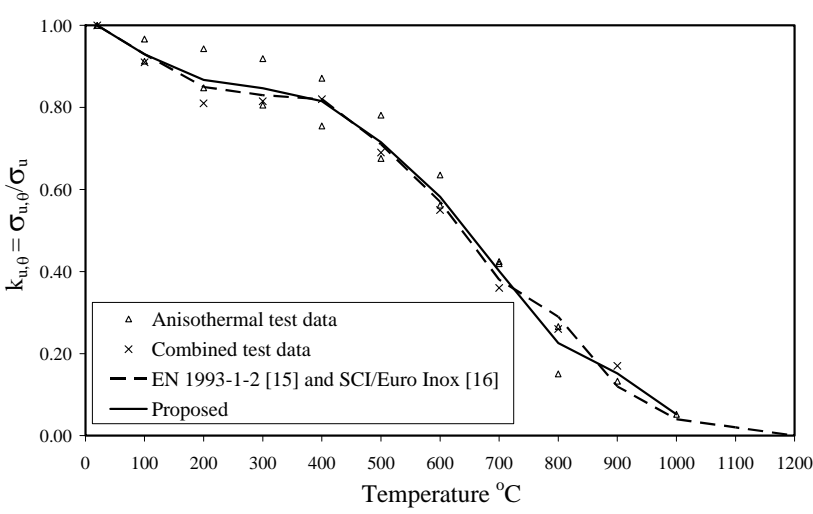

(f) Grade 1.4462 


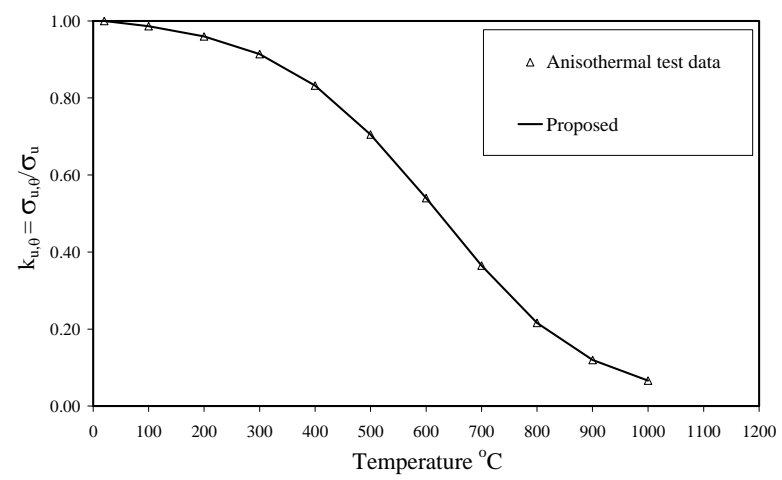

(g) Grade 1.4162 (LDX 2101)

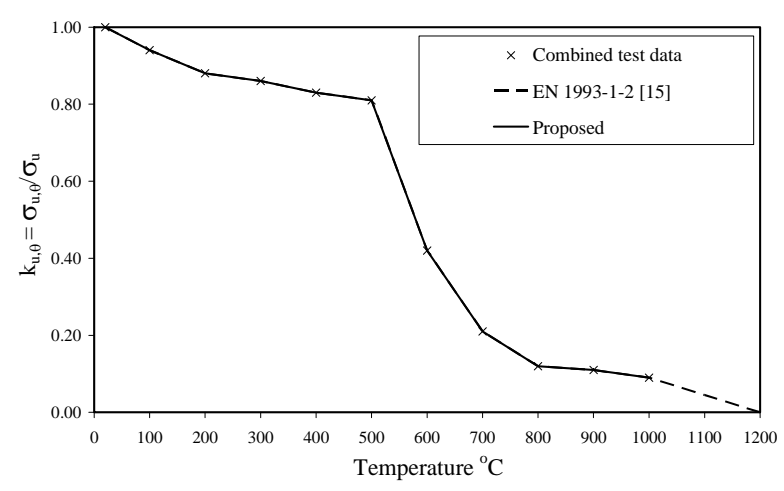

(i) Grade 1.4003

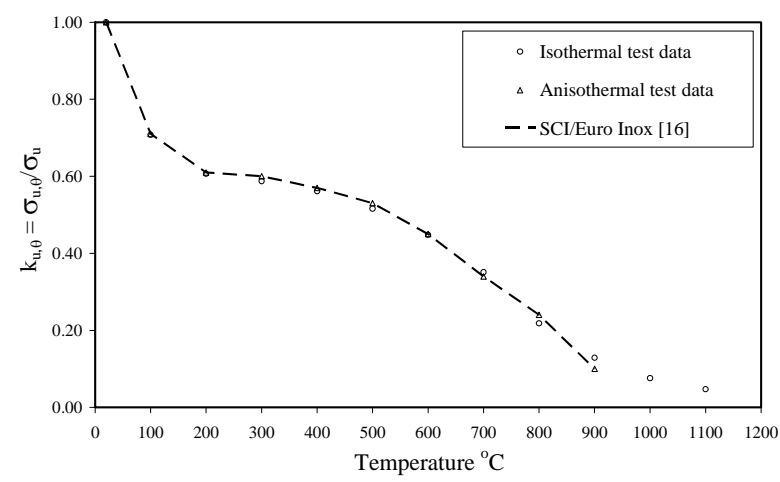

(k) Grade 1.4318 C850

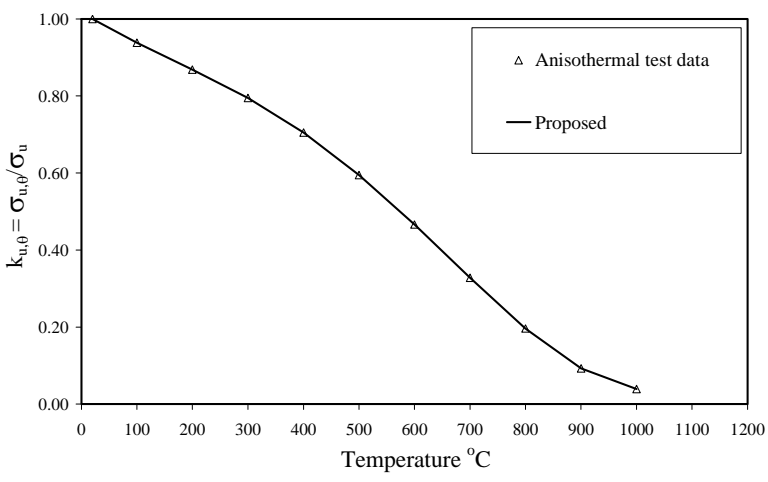

(h) Grade 1.4362

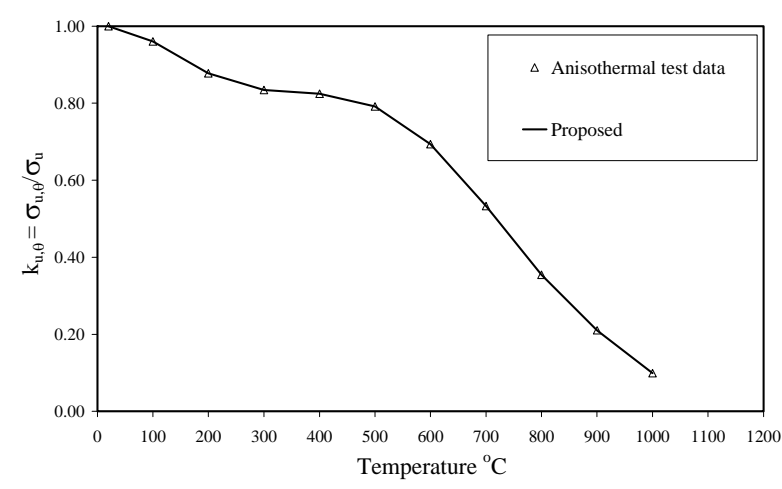

(j) Grade 1.4818

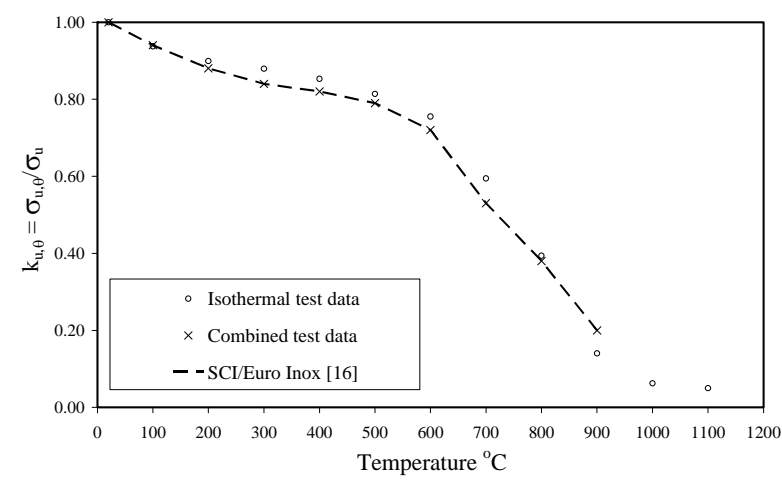

(l) Grade 1.4571 C850

Fig. 8: Proposed ultimate strength reduction factors $\mathrm{k}_{\mathrm{u}, \theta}$ for different stainless steel grades. 
Table 1: $0.2 \%$ strength reduction factors at elevated temperatures $k_{0.2, \theta}=\sigma_{0.2, \theta} / \sigma_{0.2}$ for all stainless steel grades.

\begin{tabular}{c|cccccccccccc}
\hline Temp $\theta^{\circ} \mathrm{C}$ & 1.4301 & 1.4318 & 1.4818 & $1.4401 / 4$ & 1.4541 & 1.4571 & 1.4362 & 1.4462 & 1.4162 & $\begin{array}{c}1.4003 \\
\begin{array}{c}1.4318 \\
\text { C850 }\end{array}\end{array} \begin{array}{c}1.4571 \\
\text { C850 }\end{array}$ \\
\hline 20 & 1.00 & 1.00 & 1.00 & 1.00 & 1.00 & 1.00 & 1.00 & 1.00 & 1.00 & 1.00 & 1.00 & 1.00 \\
100 & 0.80 & 0.76 & 0.76 & 0.86 & 0.87 & 0.89 & 0.83 & 0.86 & 0.79 & 1.00 & 0.86 & 0.96 \\
200 & 0.67 & 0.64 & 0.63 & 0.72 & 0.72 & 0.82 & 0.75 & 0.72 & 0.67 & 1.00 & 0.77 & 0.95 \\
300 & 0.62 & 0.58 & 0.58 & 0.67 & 0.68 & 0.77 & 0.69 & 0.67 & 0.63 & 0.98 & 0.69 & 0.92 \\
400 & 0.58 & 0.52 & 0.56 & 0.62 & 0.63 & 0.72 & 0.58 & 0.62 & 0.59 & 0.91 & 0.68 & 0.89 \\
500 & 0.53 & 0.48 & 0.54 & 0.59 & 0.60 & 0.69 & 0.43 & 0.56 & 0.51 & 0.80 & 0.65 & 0.83 \\
600 & 0.48 & 0.44 & 0.52 & 0.58 & 0.55 & 0.65 & 0.27 & 0.45 & 0.40 & 0.45 & 0.54 & 0.81 \\
700 & 0.39 & 0.37 & 0.46 & 0.50 & 0.50 & 0.59 & 0.14 & 0.28 & 0.26 & 0.19 & 0.40 & 0.60 \\
800 & 0.27 & 0.24 & 0.35 & 0.40 & 0.42 & 0.51 & 0.07 & 0.17 & 0.14 & 0.13 & 0.23 & 0.35 \\
900 & 0.15 & 0.16 & 0.18 & 0.19 & 0.26 & 0.29 & 0.04 & 0.09 & 0.05 & 0.10 & 0.11 & 0.10 \\
1000 & 0.06 & 0.09 & - & 0.10 & 0.18 & 0.15 & - & 0.02 & 0.01 & 0.07 & - & - \\
1100 & - & 0.05 & - & - & 0.07 & - & - & - & - & - & - & - \\
\hline
\end{tabular}


Table 2: Ultimate strength reduction factors at elevated temperatures $\mathrm{ku}, \theta_{\theta}=\sigma_{\mathrm{u}, \theta} / \sigma_{\mathrm{u}}$ for all stainless steel grades.

\begin{tabular}{c|cccccccccccc}
\hline Temp $\theta^{\circ} \mathrm{C}$ & 1.4301 & 1.4318 & 1.4818 & $1.4401 / 4$ & 1.4541 & 1.4571 & 1.4362 & 1.4462 & 1.4162 & 1.4003 & $\begin{array}{c}1.4318 \\
\text { C850 }\end{array}$ & $\begin{array}{c}1.4571 \\
\text { C850 }\end{array}$ \\
\hline 20 & 1.00 & 1.00 & 1.00 & 1.00 & 1.00 & 1.00 & 1.00 & 1.00 & 1.00 & 1.00 & 1.00 & 1.00 \\
100 & 0.86 & 0.76 & 0.96 & 0.92 & 0.82 & 0.88 & 0.94 & 0.93 & 0.99 & 0.94 & 0.71 & 0.94 \\
200 & 0.77 & 0.68 & 0.88 & 0.87 & 0.73 & 0.81 & 0.87 & 0.87 & 0.96 & 0.88 & 0.61 & 0.88 \\
300 & 0.74 & 0.62 & 0.83 & 0.85 & 0.71 & 0.79 & 0.79 & 0.85 & 0.91 & 0.86 & 0.60 & 0.84 \\
400 & 0.74 & 0.59 & 0.82 & 0.84 & 0.70 & 0.79 & 0.70 & 0.82 & 0.83 & 0.83 & 0.57 & 0.82 \\
500 & 0.68 & 0.55 & 0.79 & 0.80 & 0.68 & 0.77 & 0.59 & 0.72 & 0.70 & 0.81 & 0.53 & 0.79 \\
600 & 0.59 & 0.49 & 0.69 & 0.73 & 0.61 & 0.71 & 0.47 & 0.58 & 0.54 & 0.42 & 0.45 & 0.72 \\
700 & 0.43 & 0.38 & 0.53 & 0.55 & 0.48 & 0.57 & 0.33 & 0.40 & 0.36 & 0.21 & 0.34 & 0.53 \\
800 & 0.26 & 0.25 & 0.35 & 0.34 & 0.33 & 0.38 & 0.20 & 0.23 & 0.22 & 0.12 & 0.24 & 0.38 \\
900 & 0.14 & 0.12 & 0.21 & 0.18 & 0.19 & 0.23 & 0.09 & 0.13 & 0.12 & 0.11 & 0.10 & 0.20 \\
1000 & 0.07 & 0.09 & 0.10 & 0.09 & 0.11 & 0.10 & 0.04 & 0.04 & 0.07 & 0.09 & - & - \\
1100 & - & 0.05 & - & - & 0.07 & - & - & - & - & - & - & - \\
\hline
\end{tabular}


Table 4: $0.2 \%$ strength reduction factors at elevated temperatures $\mathrm{k} 0.2, \theta=\sigma_{0.2, \theta} / \sigma_{0.2}$ for the proposed groups.

\begin{tabular}{|c|c|c|c|c|c|c|}
\hline Temp $\theta^{\circ} \mathrm{C}$ & $\begin{array}{c}\text { Austenitic I } \\
1.4301, \\
1.4318, \\
1.4818\end{array}$ & $\begin{array}{c}\text { Austenitic II } \\
1.4401 / 4, \\
1.4541\end{array}$ & $\begin{array}{c}\text { Austenitic } \\
\text { III } \\
1.4571\end{array}$ & $\begin{array}{c}\text { Duplex I } \\
1.4362\end{array}$ & $\begin{array}{c}\text { Duplex II } \\
1.4462, \\
1.4162\end{array}$ & $\begin{array}{c}\text { Ferritic } \\
1.4003\end{array}$ \\
\hline 20 & 1.00 & 1.00 & 1.00 & 1.00 & 1.00 & 1.00 \\
\hline 100 & 0.78 & 0.86 & 0.89 & 0.83 & 0.82 & 1.00 \\
\hline 200 & 0.65 & 0.72 & 0.82 & 0.75 & 0.70 & 1.00 \\
\hline 300 & 0.60 & 0.67 & 0.77 & 0.69 & 0.65 & 0.98 \\
\hline 400 & 0.55 & 0.62 & 0.72 & 0.58 & 0.60 & 0.91 \\
\hline 500 & 0.50 & 0.60 & 0.69 & 0.43 & 0.53 & 0.80 \\
\hline 600 & 0.46 & 0.56 & 0.65 & 0.27 & 0.42 & 0.45 \\
\hline 700 & 0.38 & 0.50 & 0.59 & 0.14 & 0.27 & 0.19 \\
\hline 800 & 0.25 & 0.41 & 0.51 & 0.07 & 0.15 & 0.13 \\
\hline 900 & 0.15 & 0.22 & 0.29 & 0.04 & 0.07 & 0.10 \\
\hline 1000 & 0.07 & 0.14 & 0.15 & - & 0.01 & 0.07 \\
\hline 1100 & 0.05 & 0.07 & - & - & - & - \\
\hline
\end{tabular}


Table 5: Ultimate strength reduction factors at elevated temperatures $\mathrm{ku}, \theta_{\theta}=\sigma_{\mathrm{u}, \theta} / \sigma_{\mathrm{u}}$ for the proposed groups.

\begin{tabular}{|c|c|c|c|c|c|c|}
\hline $\begin{array}{l}\text { Temp } \theta \\
{ }^{\circ} \mathrm{C}\end{array}$ & $\begin{array}{c}\text { Austenitic I } \\
1.4301, \\
1.4318, \\
1.4818 \\
\end{array}$ & $\begin{array}{c}\text { Austenitic II } \\
1.4401 / 4, \\
1.4541\end{array}$ & $\begin{array}{c}\text { Austenitic III } \\
1.4571\end{array}$ & $\begin{array}{c}\text { Duplex I } \\
1.4362\end{array}$ & $\begin{array}{c}\text { Duplex II } \\
1.4462, \\
1.4162\end{array}$ & $\begin{array}{c}\text { Ferritic } \\
1.4003\end{array}$ \\
\hline 20 & 1.00 & 1.00 & 1.00 & 1.00 & 1.00 & 1.00 \\
\hline 100 & 0.81 & 0.87 & 0.88 & 0.94 & 0.96 & 0.94 \\
\hline 200 & 0.72 & 0.80 & 0.81 & 0.87 & 0.91 & 0.88 \\
\hline 300 & 0.68 & 0.78 & 0.79 & 0.79 & 0.88 & 0.86 \\
\hline 400 & 0.66 & 0.77 & 0.79 & 0.70 & 0.82 & 0.83 \\
\hline 500 & 0.61 & 0.74 & 0.77 & 0.59 & 0.71 & 0.81 \\
\hline 600 & 0.54 & 0.67 & 0.71 & 0.47 & 0.56 & 0.42 \\
\hline 700 & 0.40 & 0.51 & 0.57 & 0.33 & 0.38 & 0.21 \\
\hline 800 & 0.25 & 0.34 & 0.38 & 0.20 & 0.22 & 0.12 \\
\hline 900 & 0.13 & 0.19 & 0.23 & 0.09 & 0.14 & 0.11 \\
\hline 1000 & 0.08 & 0.10 & 0.10 & 0.04 & 0.06 & 0.09 \\
\hline 1100 & 0.05 & 0.07 & - & - & - & - \\
\hline
\end{tabular}

